\title{
DIFFUSE BRONCHOPULMONARY ASPERGILLOSIS
}

\author{
BY \\ A. O. BECH \\ From the Coventry and Warwickshire Hospital, Coventry
}

(RECEIVED FOR PUBLICATION JANUARY 27, 1961)

Diffuse bronchopulmonary aspergillosis is a comparatively rare condition. The number of reported cases in the more recent literature are few, where confirmation has been obtained from the study of necropsy material or of material obtained by pulmonary resection.

In this paper two cases of diffuse bronchopulmonary aspergillosis are reported in detail. The post-mortem findings and histology are described; the relevant literature is also reviewed.

\section{MYCOLOGY}

Aspergillosis is caused by certain species of aspergillus, which belongs to the group of filamentous fungi.

The morphological appearance of the different species pathogenic to man and their cultural characteristics have been fully described by Thom and Raper (1945), by Ross (1951), by Hinson, Moon, and Plummer (1952), and by Conant, Smith, Baker, Callaway, and Martin (1954).

In the majority of cases aspergillosis is caused by $A$. fumigatus, but occasionally by $A$. niger, and only rarely have strains such as $A$. vesicular, $A$. nidulans, and $A$. flavus been described as causing disease.

\section{Pathogenesis}

Aspergillosis is acquired exogenously and the infective element is the spore. These organisms are only occasionally pathogenic to man and tend to produce localized disease. Dissemination in the lungs is very rare and may be accompanied by haematogenous spread to other organs, which appears to depend on the ability of the mycelium to penetrate blood vessels. In non-viable lung tissue where conditions are anaerobic, fungus mycelium colonizes, but under aerobic conditions sporulation may occur. In human disease preexistent tissue damage appears to be a prerequisite, unlike avian disease where primary infection can occur. Gowing and Hamlin (1960) consider that the fungi reach the alveoli in invasive aspergillosis, either by aspiration into the respiratory bronchioles and alveolar ducts with subsequent spread into the associated alveolar sacs and alveoli or by colonization of the mucosa of the bronchi and then spreading through their walls. Riddell (1958) has expressed the opinion that once infection is established changes occur in the adjacent tissues which may promote further invasion by the fungus. He considers it likely that these changes are produced by diffusible products of fungi growing in non-viable lung tissue, which evoke a variable inflammatory reaction or tissue degeneration in adjacent viable lung tissue. The tissue reactions most often seen are necrotic, granulomatous, inflammatory, or suppurative. Riddell (1958) considers that the pathogenic'ty of A. fumigatus as compared with other species is related to special products of fungal metabolism rather than to its structure.

\section{CAse Reports}

CASE 1.-The patient, a car machinist aged 42, was admitted to hospital on the fourteenth day of a respiratory infection. The illness began with pyrexia, cough with copious sputum, lassitude, moderate dyspnoea, and pleuritic left chest pain. At the start of the illness he was given sulphamerazine by mouth for three days. On the seventh day of the illness he developed pain in the right calf and swelling of the right leg. At 12 years of age he had had a left lung abscess treated by needling. For a year he had noticed a slight morning cough with sputum and slight dyspnoea on exertion. A mass radiograph 18 months before revealed slight mediastinal shift to the left, pleural thickening at the left costophrenic angle, and an increase of translucency at both bases.

Examination revealed a rather wasted, acutely ill man. There was slight finger clubbing and moderate dyspnoea, but no cyanosis. The trachea was slightly deviated to the left. The movements of the left lower chest were restricted and dullness extended from the left axilla to the base. Over the left lower zone breath sounds were diminished and rales were audible. There was thrombophlebitis of the left leg. The remainder of the examination was normal. 


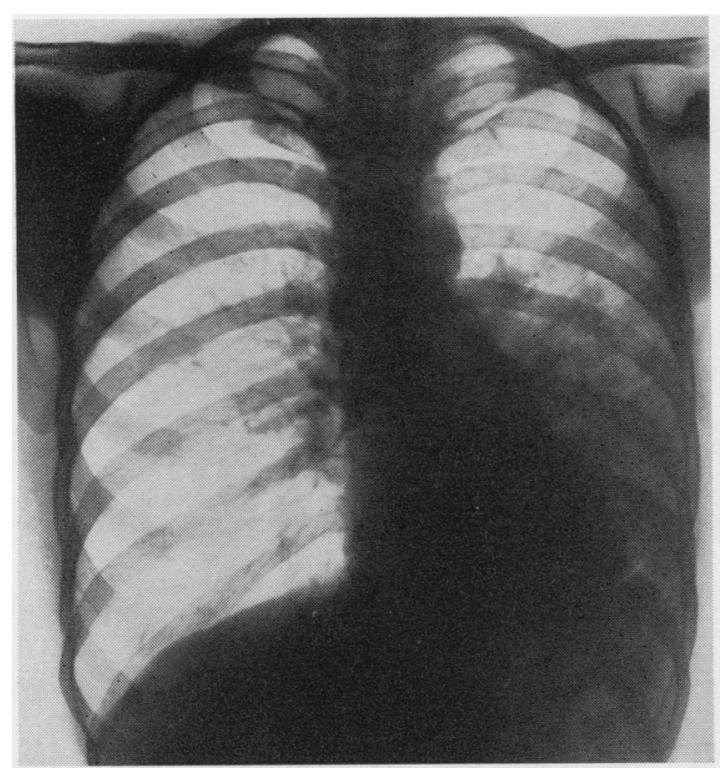

Fig. 1.-Case 1 on admission.

The initial radiograph (Fig. 1) showed confluent consolidation in the left lower zone with patchy consolidation in the left mid zone, also a small basal effusion. The mediastinum was slightly drawn to the left. The initial blood count showed a leucocyte count of 10,500 per c.mm. ( $80 \%$ polymorphs, $12 \%$ lymphocytes, $4 \%$ monocytes, and $4 \%$ metamyelocytes). The haemoglobin level was 13.0 g. $/ 100 \mathrm{ml}$. The Westergren sedimentation rate was $70 \mathrm{~mm}$. in one hour. Subsequently the leucocyte count on the seventh day after admission was 24,000 per c.mm. with $90 \%$ polymorphs and on the 40th day 16,000 per c.mm. with $93 \%$ polymorphs. Examinations of sputum throughout the illness contributed nothing. The initial culture revealed a moderate mixed growth with alpha streptococci predominating; in later cultures coagulase-negative staphylococci also predominated. Repeated cultures were negative for acid-alcohol-fast bacilli. The pleural fluid was straw coloured and sterile on culture. Examination of the urine was normal. The details of treatment are seen on the chart (Fig. 2), which also shows the temperature, pulse, and respiratory rates.

During the first nine days the temperature, pulse, and respiratory rates slowly rose. He became more breathless and complained of pain in the right chest. Moist sounds and a pleural rub developed in the right lung and were followed by signs of definite consolidation in the upper and mid zones. A radiograph (Fig. 3) on the eighth day after admission revealed patchy consolidation in the right upper and mid zones. The thrombophlebitis had by then settled. Liver function tests were normal. The total protein was 5.8 g. $/ 100 \mathrm{ml}$. (albumin 2.0 , globulin 3.3).

During the next 16 days the temperature was only slightly elevated, but the pulse and respiratory rates were high. He remained extremely short of breath. There was persistent slight cyanosis and yellow discoloration of the skin, progressive emaciation, and increased weakness. Periods of lucidity alternated with stupor and delirium. The liver was slightly enlarged. The sputum was thick and mucopurulent. On the sixteenth day urine analysis revealed $30 \mathrm{mg} . /$ $100 \mathrm{ml}$. of albumin. Serial radiographs showed persistent left basal consolidation and patchy dense consolidation in the right upper and mid zones, also the presence of a number of cavities.

On the twenty-fifth day he was breathless at rest, grossly wasted, and very weak. The blood urea level had risen to $57 \mathrm{mg}$. $/ 100 \mathrm{ml}$. Bronchoscopy revealed a normal appearance although profuse pus was seen coming from the lower lobe bronchi. Tracheotomy was performed and a wide tracheotomy tube inserted. Frequent suction was then carried out. An intravenous infusion of normal saline and a blood transfusion were given. A radiograph then (Fig. 4) revealed dense consolidation involving most of the right lung and the presence of cavities in the upper and mid zones, also residual consolidation at the left base. On the thirty-first day the total protein was $5.7 \mathrm{~g}$./ $100 \mathrm{ml}$. (albumin 1.7, globulin 4.0), the blood urea $115 \mathrm{mg} . / 100 \mathrm{ml}$. and the arterial oxygen saturation $58.0 \%$. Trapped sputum from the tracheotomy showed large masses of pus cells and very scanty bacteria. Four cultures yielded a coliform bacillus in pure culture on one plate and in the other three in association with saprophytic staphylococci.

Clinical deterioration continued. During the six days before his death he received continuous intravenous infusions of normal saline. A radiograph taken (Fig. 5) during the last week showed fresh shadowing in the left upper zone. He died on the 56 th day of his illness, 42 days after admission to hospital. At no stage during his illness was an aspergillus isolated.

CASE 2.- The patient, a coal merchant of 54, was admitted to hospital on the seventh day of a respiratory illness. The illness began with cough and sputum, dyspnoea, pleuritic right chest pain, and considerable malaise, also headache and insomnia. Since boyhood he had been subject to recurrent bronchitis and for some years he had had a productive cough. He had lately put on weight and become slightly short of breath on exertion.

Examination revealed an ill man. The chest was emphysematous. The percussion note was impaired at the right base where the air entry was diminished. A chest radiograph showed consolidation above the right diaphragm, involving the basal segments of the right lower lobe, also some generalized increase in lung markings.

Examinations of sputum throughout the illness contributed nothing. The initial culture revealed a mixed growth with alpha streptococcus predominating. Repeated cultures for acid-alcohol-fast bacilli were negative. Examination of urine was normal. The details of treatment are seen on the chart (Fig. 6), 


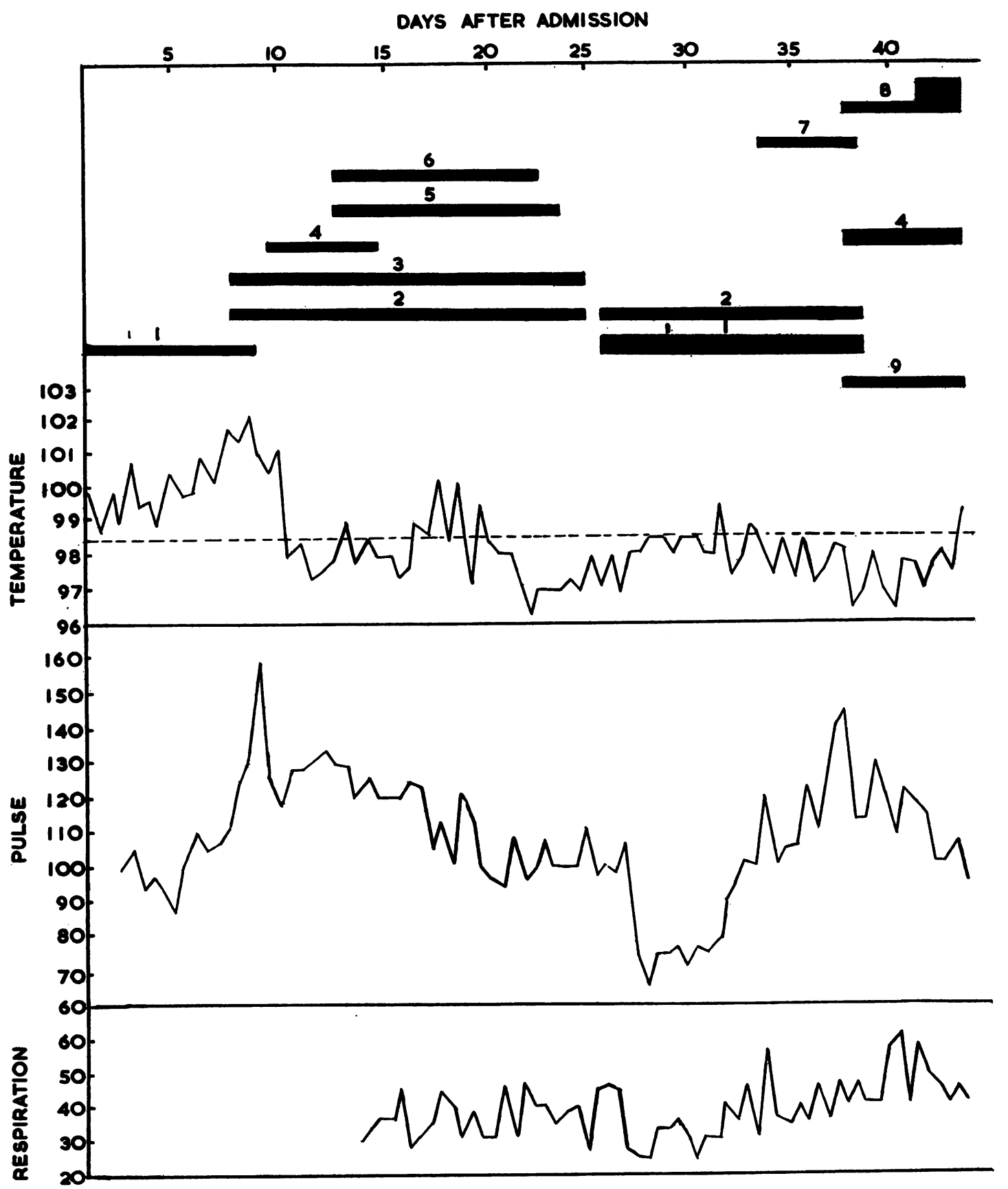

FIG. 2.-Case 1: chart shows details of treatment. (1) Penicillin, 1 meg. unit intramuscularly daily first course, 2 meg. units second course; (2) streptomycin sulphate $1 \mathrm{~g}$. intramuscularly daily; (3) isoniazid $200 \mathrm{mg}$. daily; (4) chloromycetin 250 mg. q.i.d. first course, $500 \mathrm{mg}$. q.i.d. second course; (5) erythromycin $200 \mathrm{mg}$. six hourly; (6) rovamycin $1.0 \mathrm{~g}$. six hourly; (7) terramycin $500 \mathrm{mg}$. six hourly; (8) amphotericin B $12.5 \mathrm{mg}$. intravenously daily, increased to $50 \mathrm{mg}$. for three days; (9) cortisone 100 mg. intramuscularly daily. 
Fig. 3.-Case 1 eight days after admission.

Fig. 4.-Case 125 days after admission.

Fig. 5.-Case 137 days after admission.

Fig. 6.-Case 2: chart shows details of treatment. (1) Seclomycin one vial intramuszularly b.d. (one vial contains 100,000 units sodium penicillin $G, 300,000$ units procaine penicillin 8 , and $0.5 \mathrm{~g}$. streptomycin), (2) procaine penicillin G, 300,000 units intramuscularly b.d.; (3) sulphadiazine g. 4 stat., then $1 \mathrm{~g}$. four hourly; (4) terramycin $250 \mathrm{mg}$. six hourly.

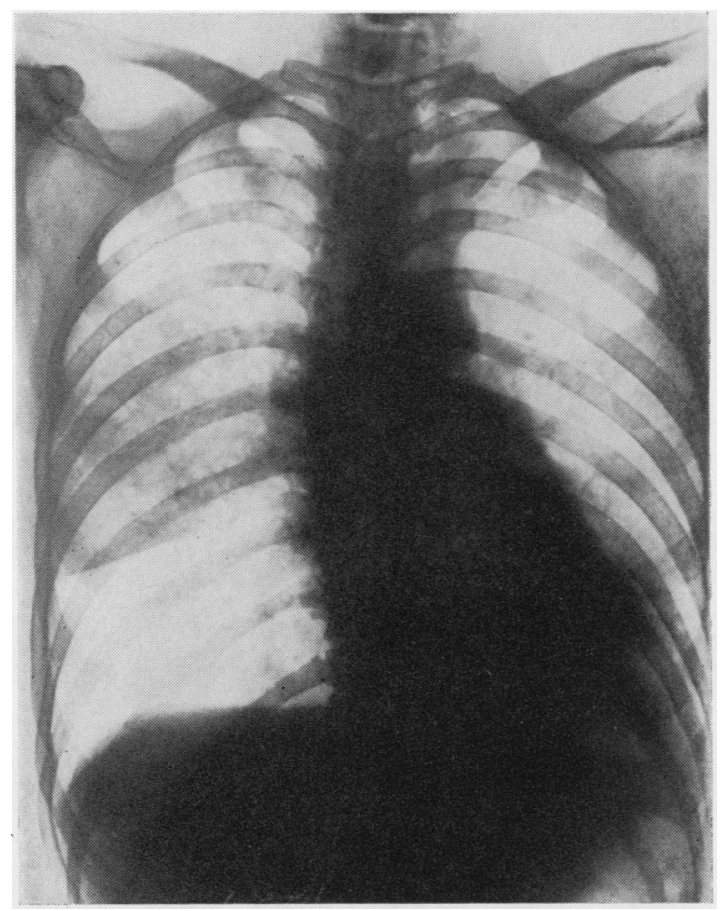

FIG. 3

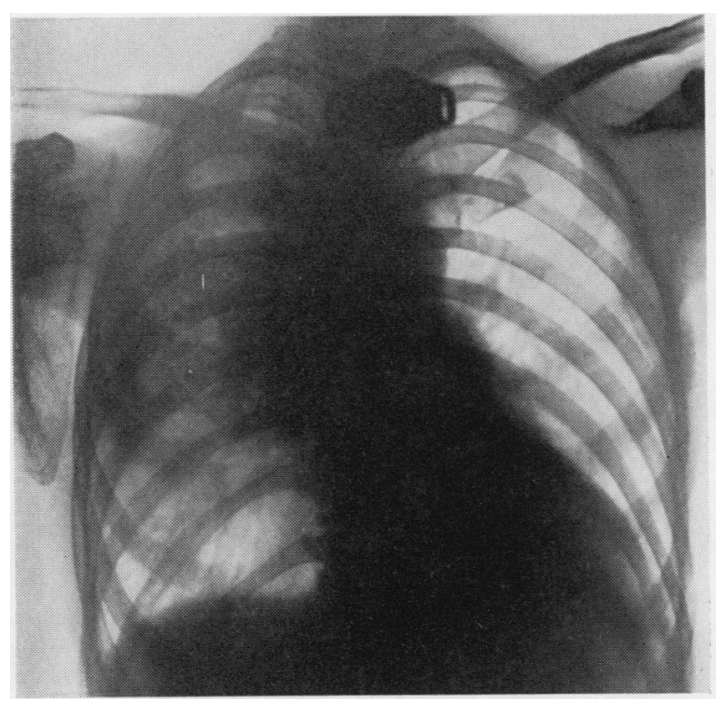

FIG. 4

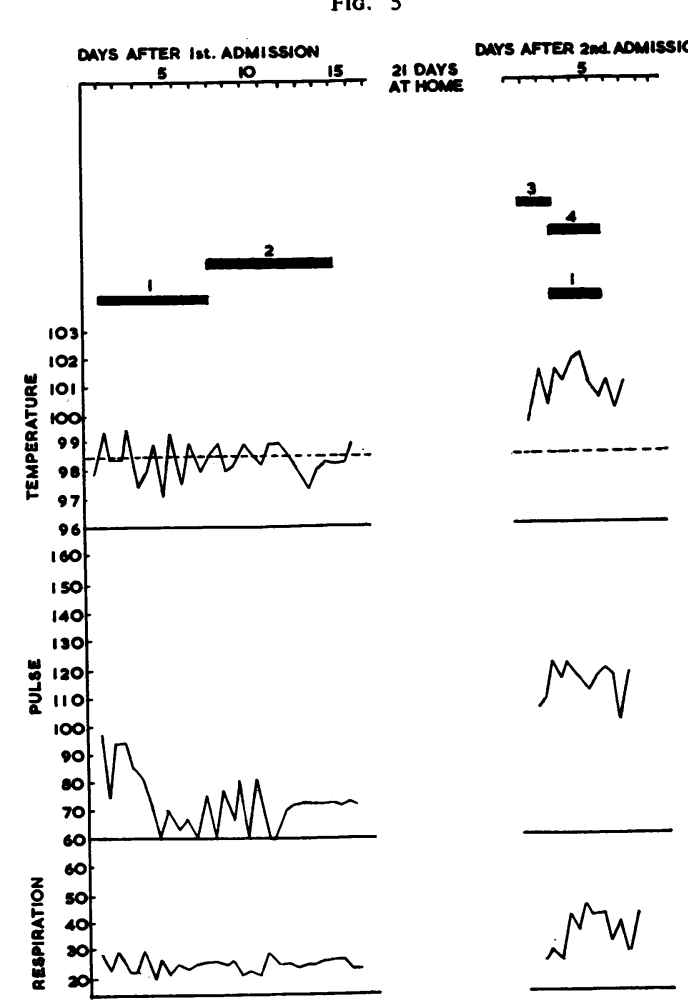

FIG. 6

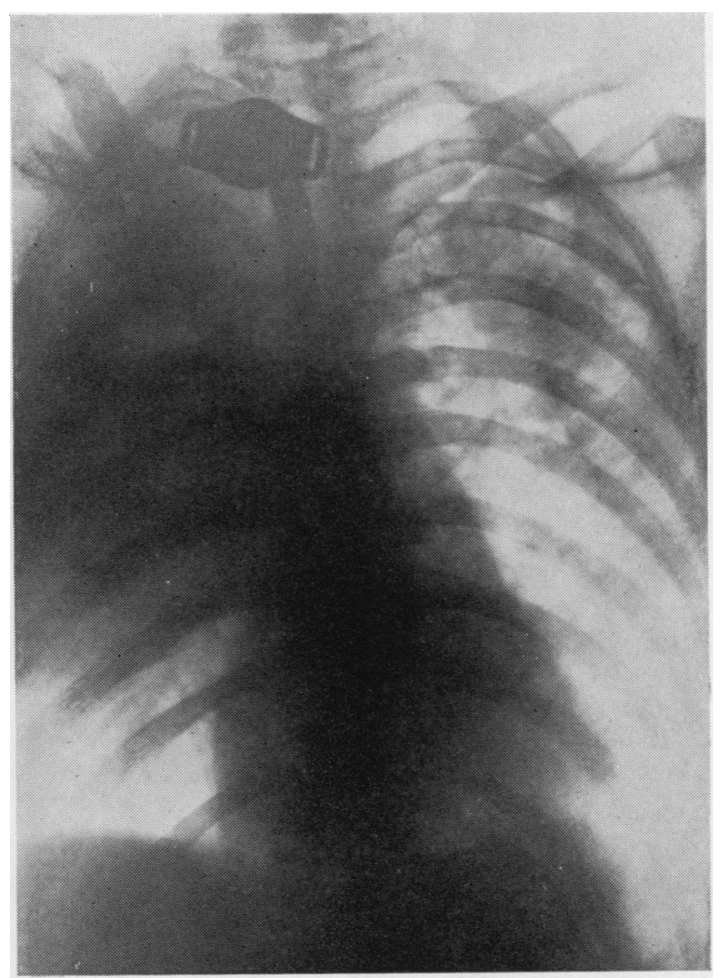

Fio. 5 
which also shows the temperature, pulse, and respiratory rates.

He improved clinically and was sent home on the sixteenth day. A radiograph before discharge revealed almost complete resolution of the right lower lobe consolidation.

Twenty-one days after discharge he was readmitted to hospital with pain in the right upper chest, marked dyspnoea, cough with purulent sputum, and profound lassitude. Examination revealed a very ill man with slight central cyanosis. The percussion note was impaired over the right upper zone where crepitations could be heard. The rest of the examination was normal. A radiograph (Fig. 7) revealed consolidation involving most of the right lung, dense and confluent in the mid zone and patchy in the upper and lower zones. The haemoglobin was $86 \%$, the leucocyte count 6,000 per c.mm. (86\% polymorphs, $2 \%$ eosinophils, $5.3 \%$ lymphocytes, $5 \%$ monocytes, $1 \%$ Türk cells, and $0.7 \%$ myelocytes). The temperature, pulse, and respiratory rates remained elevated and his clinical state steadily deteriorated. He died from a pulmonary embolism seven days after readmission, 44 days after the first admission, and 51 days after the onset of the illness. At no stage during his illness

\section{BECH} was an aspergillus isolated.

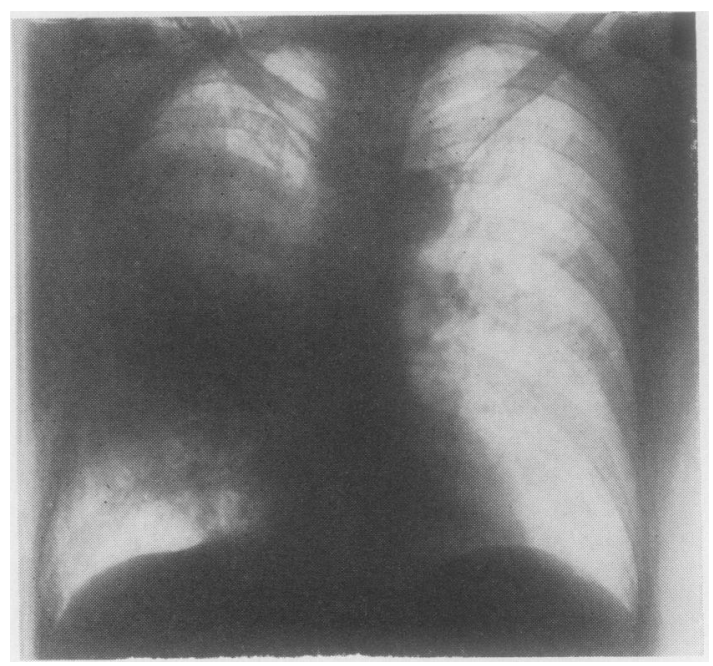

FIG. 7.-Radiograph of Case 2 on readmission.

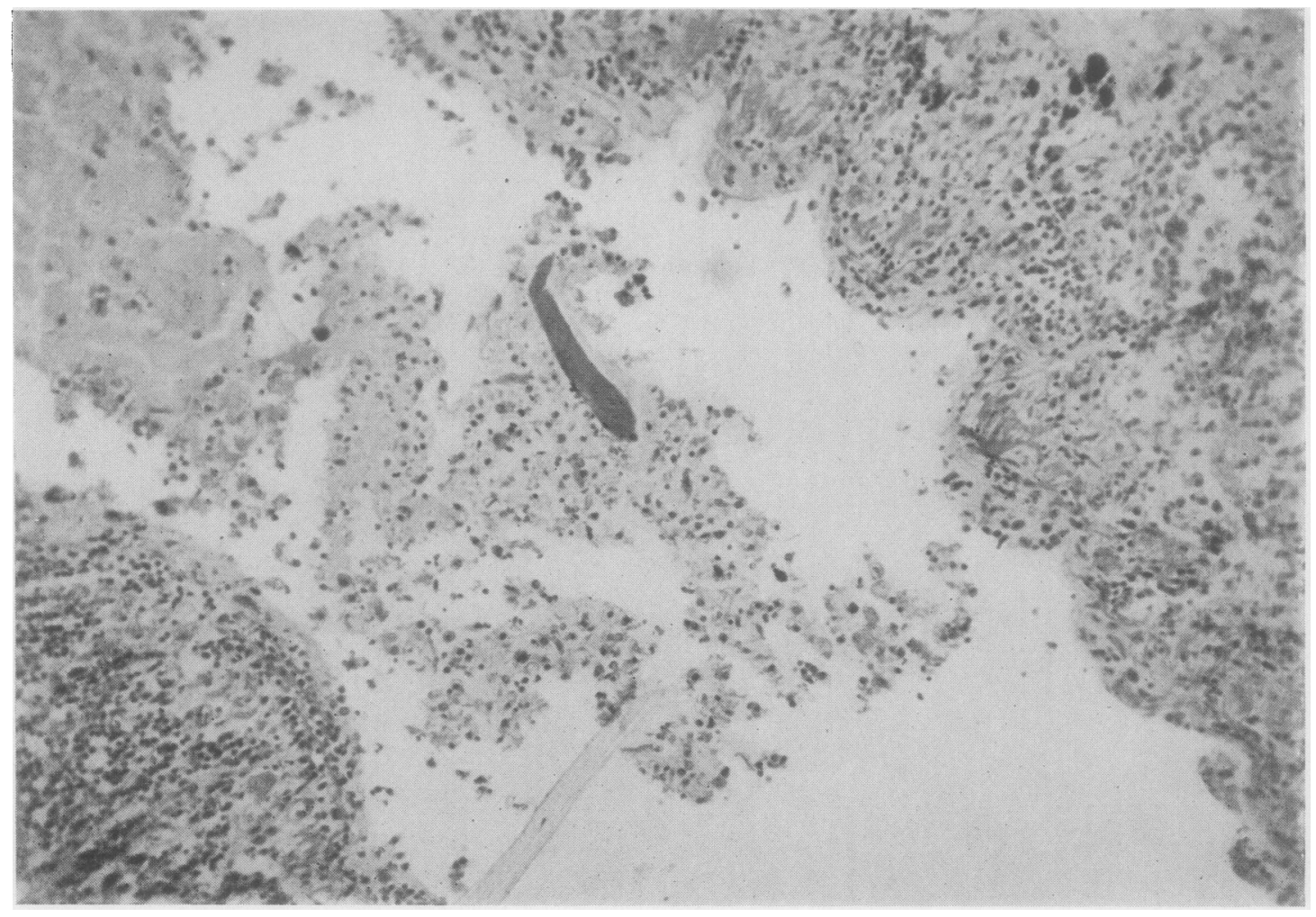

FIG. 8.-Lung section showing a small bronchus with a necrotic bronchial mucosa and an inflammatory exudate in its lumen, also variable inflammatory changes in the lung tissue. 


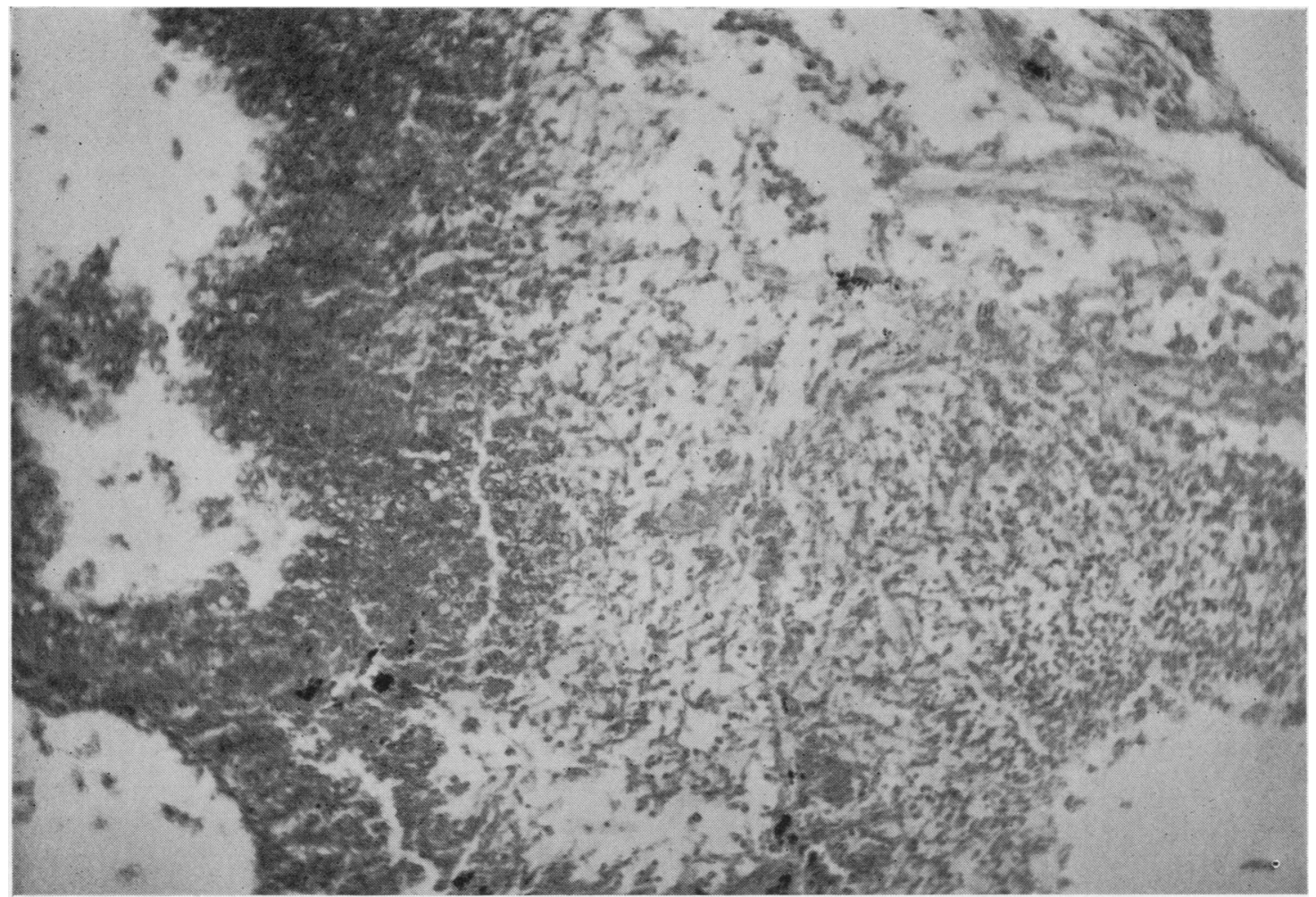

FIG. 9.-Lung section showing spore-bearing exudate, also areas of destroyed lung and inflammatory exudate.

\section{Pathological Findings}

CASE 1.-The trachea and main bronchi contained thick grey mucopus. Almost the whole of the right lung was airless and bulky, its cut surfaces being firm, grey, and oedematous ; they did not yield on pressure. At three points in the right upper lobe and at the apex of the right lower lobe there were abscess cavities with ragged yellow-grey walls and central brownish-grey sloughs. No sulphur granules were seen. The largest cavity, that in the anterior part of the right upper lobe, was about $6 \mathrm{~cm}$. in diameter and impinged anteriorly on the sternum. Both pleural cavities were largely obliterated by adhesions. The left lung, and particularly the left lower lobe, showed somewhat similar changes to the right, although they were less pronounced. There was an abscess cavity in the left lower lobe. An antemortem thrombus was present in one branch of the right upper lobe artery. There was no evidence of aspergillus infection in other viscera.

CASE 2.-The trachea and bronchi contained viscid mucus. The whole of the right lung was consolidated with a necrotic area in the anterior part of the upper lobe. The left lung had partly collapsed. Antemortem thrombi were present in the pulmonary artery. There was no evidence of aspergillus infection in other viscera.
CASE 1.-The sloughs in the cavities in the lungs were in reality fungal colonies made up of multiple, ramifying, branching, septate mycelia with coarse hyphal swellings, but without fructification. The organism appeared to be confined to the cavities; the remainder of the lung showed varying degrees of exudation, organization, and alveolar haemorrhage (Figs. 8 and 9).

CASE 2.-Sections of the lung showed a pneumonic consolidation with early organization. In places this resolution had not taken place, but the process had gone on to one of suppuration. Here the microanatomy of the lung was destroyed and replaced by sheets of polymorphs in an exudate. At about the junction of the two areas the lung had been colonized by a fungus which showed septate mycelia in radial arrangement (Fig. 10).

Mycology and Bacteriology.-In Case 1 examination of swabs from the lungs revealed aspergilli. Culture for organisms yielded coagulase-negative staphylococci and coliforms, for acid-alcohol-fast bacilli no growth, and for fungus $A$. fumigatus.

Swabs were not taken at necropsy in Case 2. The fungus seen in the section morphologically resembled an aspergillus. 


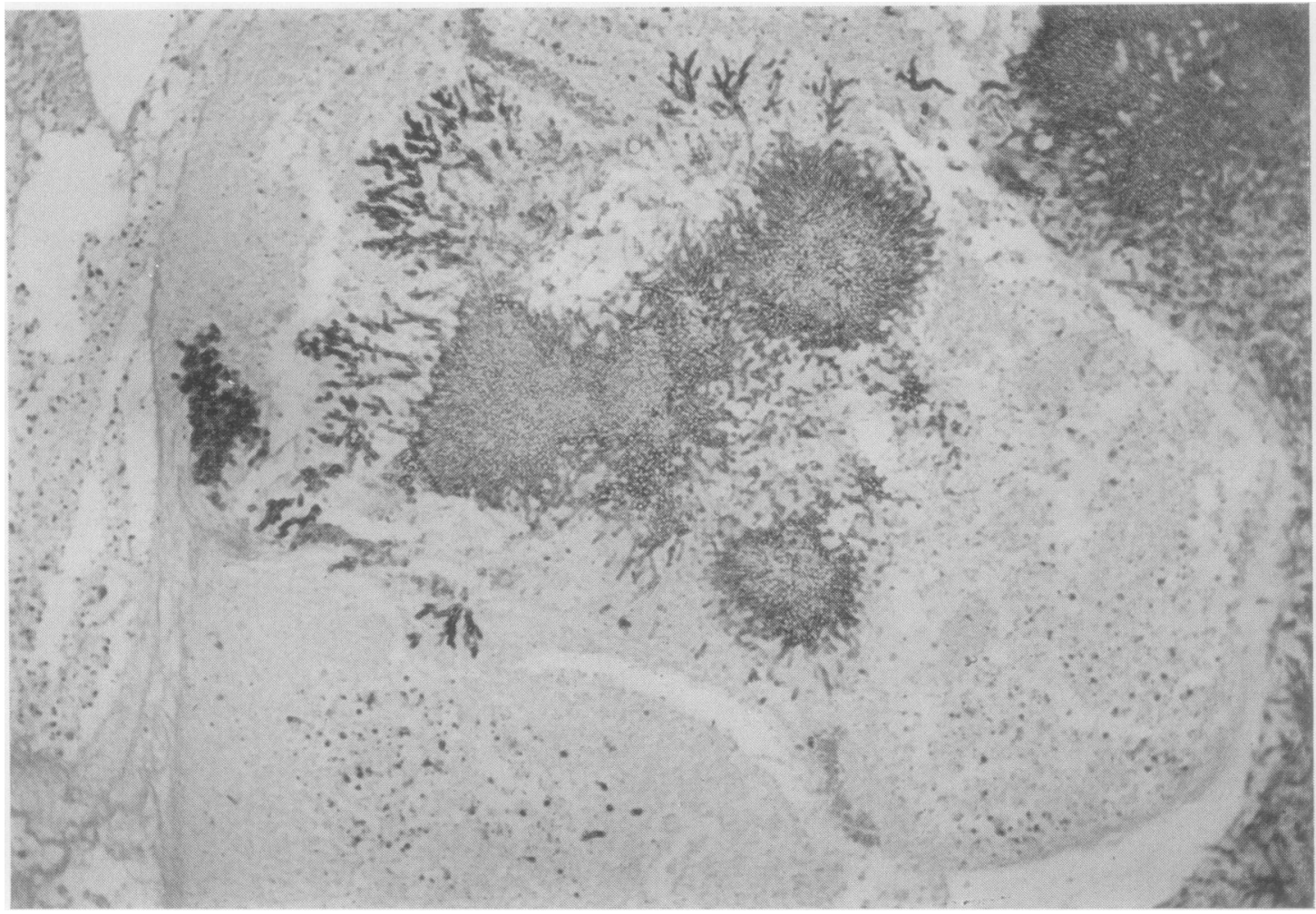

FIG. 10.-Lung section showing lung destrustion and inflammatory exudate with colonies of septate mycelia in radial arrangement.

\section{Historical Review}

Comparable cases of diffuse bronchopulmonary aspergillosis, as represented by Cases 1 and 2, with an acute suppurative type of tissue reaction have been recorded by Abbott, Fernando, Gurling, and Meade (1952), by Darke, Warrack, and Whitehead (1957), and by Toigo (1960). These cases presented as acute respiratory infections, and following antibiotic therapy the fungal infections spread rapidly in the lungs and led to cavity formation. Welsh and McClinton (1954) reported the case of a man suffering from gross subcutaneous infection with pulmonary mycotic abscesses who had been treated with antibiotics and died from intestinal haemorrhage. Hetherington (1943) described a case which ran a more protracted course and had been treated with radiotherapy and chemotherapy.

Comparable cases with a non-suppurative necrotizing tissue reaction have been reported by Naji (1959) and by Bariéty, Poulet, Monod, and de Brux (1957). The former was a case with agranulocytosis which had been treated with steroids and antibiotics. In the latter case the infection was limited to one lobe and the patient survived pulmonary resection. Hertzog, Smith, and Goblin (1949) described a further case with a granulomatous tissue reaction which had received antibiotics and chemotherapy.

Cases of diffuse bronchopulmonary aspergillosis with a limited spread by the blood stream to other organs and with a tissue response of necrosis and abscess formation have been described by Linck (1939), by Welsh and Buchness (1955), and by Akkoyunlu and Yucel (1957). With the exception of Linck's case, these cases had received antibiotics. The case described by Welsh and Buchness had a neutropenia and received steroids.

Cases with infection widely disseminated to many organs and a tissue response of necrosis and abscess formation have been described (Gerstl, Weidman, and Newmann, 1948 ; Grekin. Cawley, and Zheutlin, 1950 ; Rankin, 1953 ; Levy and Cohen, 1955), and three cases by Grcevic and Matthews (1959). In the cases described by Gerstl et al. and Rankin agranulocytosis was present, and in that described by Levy and Cohen there was an undetermined haemorrhagic condition with 
anaemia, thrombocytopenia, and a marrow picture of acute blastic anaemia. Antibiotics were given in all these cases, steroids in the case described by Levy and Cohen, and in one of the cases described by Grcevic and Matthews (1959). Finegold, Will, and Murray (1959) reported a further case, that of a woman who was suffering from a septic abortion with shock and acute renal failure, who had received antibiotics. Cawley (1947) and Tobler and Minder (1954) have described similar cases with a granulomatous tissue reaction and abscess formation.

The tissue reactions in five of these cases were suppurative, in 13 necrotizing, and in three granulomatous with abscess formation. Dissemination was present in 13 cases. Marrow depression was present in five cases: three had an agranulocytosis, one a neutropenia, and one a leucopenia and thrombocytopenia. Antibiotics were given in 19 cases and five received steroids as well. One had no treatment and one received chemotherapy and radiotherapy.

Aspergilli were isolated from the sputum in only a few of the cases which have been reviewed (Hetherington, 1943 ; Darke et al., 1957). The fungus was isolated from an abscess in the case described by Cawley (1947) and from the urine of that described by Levy and Cohen (1955). Mycelia were, however, found in the tissues in all cases and identified in most. In the majority the causal organism was $A$. fumigatus. $A$. niger was found in the cases described by Hetherington (1943) and Toigo (1960), and A. flavus in that described by Naji (1959). In some cases the exact species were not identified, but in these the mycelia were considered indistinguishable from aspergilli on morphological grounds.

In recent years cases of agonal invasive bronchopulmonary aspergillosis found at routine necropsy have been reported by Cooper (1946), Ross (1951), Antopol and Quittner (1952), Zettergren and Sjöström (two cases, 1953), Zimmerman (two cases, 1955), Kirschstein and Sidransky (1956), Torack (three cases, 1957), Finegold et al. (five cases, 1959), and Gowing and Hamlin (five cases, 1960). Hodgkin's disease was present in four of these cases, leukaemia in nine, carcinoma in three, and severe infections in five. The type of pulmonary lesion in 10 cases was suppurative, in 10 necrotizing, and in one granulomatous with abscess formation. Dissemination was present in six cases. Four cases had a leucopenia, two a pancytopenia, and one had an aplastic myeloid leukaemia. One case had been treated with steroids alone, six with antibiotics alone, and 14 had received two or more forms of treatment. Of the latter group 14 had received steroids, 10 antibiotics, seven antimetabolites or radiomimetic drugs, and one radiotherapy. A. fumigatus was isolated in seven cases, $A$. flavus in two, and $A$. niger in one. In the remaining cases the mycelia were morphologically indistinguishable from aspergilli.

Sidransky and Friedman (1958) recorded five further cases, which had been treated with steroids and antibiotics. A. flavus was isolated in three of these cases. Uehlinger (1959) described a case where the pulmonary lesions in a case of generalized tuberculosis were invaded by mycelium. The patient had agranulocytosis and had received antibiotics and steroids. Neilson (1959) described the case of a woman known to have a solitary bronchogenic cyst who had been treated with radiotherapy following mastectomy for carcinoma. The cyst became infected and treatment was given with antibiotics. After resection of the lobe, the cyst, the cyst wall, and adjacent lung tissue were found to be infected with the mycelium of $A$. niger.

\section{Discussion}

Susceptibility to invasive aspergillosis appears to be enhanced by certain factors. These are therapy with antibiotics and chemotherapeutic drugs, with steroids, radiotherapy, therapy with antimetabolites and radiomimetic drugs, depression of bone marrow activity, debility, and general diseases such as Hodgkin's disease, leukaemia, carcinoma, and severe infection. Of these, antibiotics and steroids would appear to be the most significant. In the majority of the cases which have been reviewed from the literature, antibiotics in massive dosage were given and in a large proportion steroids. Some of the other factors played a part in most of these cases.

It appears that antibiotics may affect the fungi, the host, or both. They may stimulate the growth and virulence of the infecting fungus. By destruction of competing bacterial flora they enable the fungus to multiply excessively. The destruction of vitamin synthesizing bacteria causes the development of an avitaminosis with consequent lowering of resistance to infection by the multiplying fungus. Chemotherapeutic drugs probably act in a similar manner.

Steroids appear to alter leucocyte response to injury either by vascular change, direct depression. or by deranged hormonal control. They also cause a deranged immunological response and by depressing antibody synthesis they may permit unlimited multiplication in the tissues of ordinarily 
non-pathogenic fungi which become highly pathogenic. At the same time they alter the activity of the host tissue, so leading to unusually severe degeneration and necrosis in susceptible lung tissue.

In the two cases which have been presented it seems likely that the disease started as a bacterial infection and that the fungus infection followed as a fatal complication. In the first the invasion probably occurred fairly early in the course of the illness and in the second at a later stage. There can be little doubt that in both cases the massive and varied antibiotic therapy stimulated the growth of the fungus and probably its virulence and paved the way for its multiplication and spread.

A diagnosis of invasive aspergillosis is always difficult to make, but this condition should be suspected where there is continued clinical deterioration and extension of disease in the lungs, in spite of apparently adequate antibiotic therapy and especially if steroids have also been given. The finding of mycelium in the sputum can be misleading, as it may be present as a saprophyte or contaminant. In the cases reviewed from the literature mycelium was only present in the sputum of a small minority. The repeated finding of mycelium, however, may be significant. The radiographic appearances are also likely to be somewhat varied.

\section{SUMMARY}

Two cases of diffuse bronchopulmonary aspergillosis with suppurative pulmonary lesions are presented in which antibiotic treatment appeared to have been the main factor in the initiation and spread of the fungal infection.

Most of the cases of invasive aspergillosis reported in the literature in recent years have also been briefly reviewed and analysed.
My thanks are due to Dr. James Sharkey for allowing me to publish Case 2, to Dr. M. K. Alexander and Dr. S. B. van der Merwe for the pathological reports, to Mr. L. Hine for the photomicrographs, and to Miss K. Kennedy for secretarial assistance.

\section{REFERENCES}

Abbott, J. D., Fernando, H. V. J., Gurling, K., and Meade, B. W. (1952). Brit. med. J., 1, 523 .

Akkoyunlu, A., and Yucel, F. A. (1957). Arch. franc. Pédiat ., 14, 615

Antopol, W., and Quittner, H. (1952). J. Mt Sinai Hosp., 19, 91.

Bariéty, M., Poulet, J., Monod, O., and Brux, J. de (1957). Bull. Soc. méd. Hôp. Paris, 73, 397.

Cawley, E. P. (1947). Arch. intern. Med., 80, 423.

Conant, N. F., Smith, D. T., Baker, R. D., Callaway, J. L., and Martin, D. S. (1954). Manual of Clinical Mycology, 2nd ed. Saunders, Philadelphia and London.

Cooper, N. S. (1946). Arch. Path. (Chicago), 42, 644.

Darke, C. S., Warrack, A. J. N., and Whitehead, J. E. M. (1957) Brit. med. J., 1, 984.

Finegold, S. M., Will, D., and Murray, J. F. (1959). Amer. J. Med., $27,463$.

Gerstl, B., Weidman, W. H., and Newmann, A. V. (1948). Ann. intern. Med., 28, 662 .

Gowing, N. F. C., and Hamlin, I. M. E. (1960). J. clin. Path., 13, 396.

Grcevic, N., and Matthews, W. F. (1959). Amer. J. clin. Path., 32, 536 .

Grekin, R. H., Cawley, E. P., and Zheutlin, B. (1950). Arch. Path. (Chicago), 49, 387.

Hertzog, A. J., Smith, T. S., and Goblin, M. (1949). Pediatrics, 4 331 .

Hetherington, L. H. (1943). Amer. Rev. Tuberc., 47, 107.

Hinson, K. F. W., Moon, A. J., and Plummer, N. S. (1952). Thorax, 7, 317.

Kirschstein, R. L., and Sidransky, H. (1956). A.M.A. Arch. Path., $62,103$.

Levy, E. S., and Cohen, D. B. (1955). A.M.A. Arch. intern. Med. $95,118$.

Linck, K. (1939). Virchows Arch. path. Anat., 304, 408.

Naji, A. F. (1959). A.M.A. Arch. Path., 68, 282

Neilson, D. B. (1959). Scot. med. J., 4, 557.

Rankin, N. E. (1953). Brit. med.J., 1, 918.

Riddell, R. W. (1958). Proc. roy. Soc. Med., 51, 491.

Ross, C. F. (1951). J. Path. Bact., 63, 409.

Sidransky, H., and Friedman, L. (1958). Amer. J. Path., 34, 585.

Thom, C., and Raper, K. B. (1945). A Manual of the Aspergilli. Williams and Wilkins, Baltimore.

Tobler, W., and Minder, W. (1954). Helv. paediat. Acta, 9, 209.

Toigo, A. (1960). Amer. Rev. resp. Dis., 81, 392.

Torack, R. M. (1957). Amer. J. Med., 22, 872.

Uehlinger, E. (1959). Schweiz. Z. Tuberk., 16, 347.

Welsh, R. A., and Buchness, J. M. (1955). Amer. J. clin. Path., 25, 782 .

and McClinton, L. T. (1954), A.M.A. Arch. Path., 57, 379.

Zettergren, L., and Sjöström, B. (1953). Acta med. scand., 147, 203 Zimmerman, L. E. (1955). Amer. J. clin. Path., 25, 46. 